\title{
Grey Wolf Optimization for Multi Input Multi Output System
}

\author{
Ahmed A. M. El-Gaafary ${ }^{1}$, Yahia S. Mohamed ${ }^{1}$, Ashraf Mohamed Hemeida ${ }^{2, *}$, Al-Attar A. Mohamed ${ }^{3}$ \\ ${ }^{1}$ Faculty of Engineering, Elminia University, Egypt \\ ${ }^{2}$ Ar-Rass Faculty of Science and Arts, Qassim University, Saudi Arabia \\ ${ }^{3}$ Faculty of Engineering, Aswan University, Egypt
}

Copyright (C) 2015 Horizon Research Publishing All rights reserved.

\begin{abstract}
Grey wolf optimizer (GWO) is a new technique, which can be applied successfully for solving optimized problems. The GWO indeed simulates the leadership hierarchy and hunting mechanism of grey wolves. There are four types of grey wolves which are alpha, beta, delta and omega. Those four types can be used for simulating the leadership hierarchy. In order to complete the process of GWO a three main steps of hunting, searching for prey, encircling prey and attacking prey are implemented. This work describes a novel meta-heuristic based on grey wolf optimization for optimum allocation of STATCOM devices on power system grid to minimized load buses voltage deviations and system power losses. Bus voltages have been solved by controlling the reactive power of shunt compensator. The Contingency management problem (such as system over-loading and a single line outages) by optimum installation of STATCOM devices, has been presented. Simulations are performed on IEEE 30-bus power system indicate that the proposed approach is a powerful search and optimization technique that may yield better solutions to engineering problems than those obtained using traditional algorithms.
\end{abstract}

Keywords Grey Wolf Optimizer (GWO), STATCOM , Contingency Management

\section{Introduction}

Optimization techniques have become more popular in the last two decades, and extended to cover different areas of study. Genetic algorithms (GA), Ant colony optimization (ACO), and particle swarms optimization (PSO) are the most well-known techniques from meta-heuristic optimization techniques[1-3].

Those techniques are the most used optimization techniques due to their simplicity, flexibility, derivation free mechanism, and local optima avoidance. The meta-heuristic optimization techniques have different advantages makes them the first choice for solving optimization problems. Their simplicity comes from being reveal of natural phenomena, animals behaviors, or evolutionary concepts[4]. Moreover they can be apply simply to different optimization problems without any change in algorithm structure, and they are the most suitable optimization techniques for real problems. Different modification techniques have been introduced to enhance the performance of (PSO) [5-12].

The concept of time-delay is introduced for improving the output results optimized by particle swarm optimization[5]. PSO may be trapped in local optima and fails to converge to global optimum. Chaotic mutation operator has been applied successfully to improve the quantum behaved particle swarm QPSO. The improvement focus on diversify the QPSO population and enhance the QPSO's behavior in preventing premature convergence to local minima[6]. PSO has been improved with difference mean based perturbation, by Kundu, et al[7].PSO is considered one of the most popular nature-inspired algorithms for real parameter optimization, so that many techniques have been applied to improve its performance[3]. The conventional PSO model doesn't ensure convergence to an optimal solution and survive from the effect of external parameters, such as acceleration parameters, and inertia weight. Crowding distance sorting technique has been applied successfully to sort particle swarm optimizer for multi-objective design optimization[8]. An erratum to the convergence of the multi-objective particle swarm optimizers has been studied and investigated by Chakraborty, et al.[9]. A modified velocity updating formula algorithm of the particle is used, for obtaining an enhanced PSO[10]. A stochastic weight deployment approach has been presented for the iterative equation of velocity updating of PSO[11]. Tabu detecting and local learning strategy in a shrunk search space have been implemented for obtaining an improved PSO[12]. Different model of PSO have been presented by Yisu, et. al, [13]. A distribution vector, and 'crossing over' are combining together to form landscape particle swarm optimizer, LSPSO. This technique provides updating the velocity and escape from local minima. The application of optimization 
techniques to FACTs devices have received a great attention from the researcher[14-20]. The improvement of transmission system loading margin with optimization based STATCOM device has been investigated using ordinal optimization (OO) [20].

In this study, grey wolf optimizer (GWO) technique is applied to multi-input multi-output electric power systems, to determine the optimum location and sizing of installing (STATCOM) devices in power systems for improving the system voltage stability. Objective functions are considered for the optimization process which is minimizing voltage deviation and power system loss. To validate the use of GWO for optimal location and optimal parameters of STATCOM, an IEEE 6M/30 bus power system is tested. The obtained results indicate the accuracy of the proposed GWO technique for the optimum allocation of STATCOM for system over-loading and a single line outages.

\section{Problem Formulation}

The optimal power flow consists of multiple objective functions is formulated to be minimize, power losses, voltage deviations and allocation of STATCOM devices (numbers and sizing).Generally the problem can be formulated as a nonlinear and constrained optimization problem [21-23]:

Minimize: $f(x, u)$

Subject to: $g(x, u)=0$;

$$
h(x, u) \leq 0
$$

where $u$ : Vector of problem control variable ; $x$ : Vector of system state variables

$f(x, u)$ : Objective function to be minimized. $g(x, u)$ : Equality constraints represents non-linear load flow equations. $h(x, u)$ : Inequality constraints.

\subsection{Minimization of Transmission lines losses}

Minimization real power loss as in [24-25] can be represented as:

$$
f_{1}\left(\mathrm{P}_{\text {Loss }}\right)=\sum_{\mathrm{i}=1}^{\mathrm{nl}} \mathrm{G}_{\mathrm{ij}}\left(\mathrm{V}_{\mathrm{i}}^{2}+\mathrm{V}_{\mathrm{j}}^{2}-2 \mathrm{~V}_{\mathrm{i}} \mathrm{V}_{\mathrm{j}} \cos \left(\delta_{\mathrm{i}}-\delta_{\mathrm{j}}\right)\right.
$$

Where $\mathrm{nl}$ is the total number of transmission lines, $\mathrm{V}$ and $\delta$ are the voltage and the voltage angle of bus respectively, and $\mathrm{G}_{\mathrm{ij}}$ is the conductance between $\mathrm{i}$ and $\mathrm{j}$ buses.

\subsection{Minimization of Voltage Deviation (VD)}

The load voltage deviation as a term of objective function $f_{2}(x, u)$ is defined as:

$$
f_{2}(V D)=\sum_{K=1}^{N L B}\left|V_{K}-V_{K}^{r e f}\right|
$$

where, NLB represents total number of load buses, $V_{K}^{\text {ref }}$ is the nominal voltage value. To have a good voltage performance, the voltage deviation at each load bus must be made as small as possible from 1.0 per unit.

\subsection{Minimization of FACTS Number and Size}

The number of STATCOM devices and its corresponding reactive power will be precisely selected by incorporated into cost function as:

$$
f_{3}(N u m b e r, \text { size })=N_{s c}+\sum_{j=1}^{N s c}\left|Q_{s c}(j)\right|
$$

Where $\mathrm{Q}_{\mathrm{sc}}$ is the STATCOM reactive power, $N_{s c}$ is the number of STATCOM Buses.

The objective function includes the total voltage deviation, the total power losses, the total STATCOM reactive power and the total STATCOM number will be described as:

$$
\mathrm{f}(\mathrm{x}, \mathrm{u})=f_{1}\left(\mathrm{P}_{\text {Loss }}\right)+f_{2}(V D)+f_{3}(\text { Number }, \text { size })
$$

In all objective functions, $x$ is the vector of dependent variable consisting of i.e. load voltages $\left(\mathrm{V}_{\mathrm{L} 1} \ldots \mathrm{V}_{\mathrm{NLB}}\right)$ and generators reactive powers $\left(\mathrm{Q}_{\mathrm{G} 1} \ldots \mathrm{Q}_{\mathrm{gNG}}\right)$, where $u$ is the vector of independent variables here reactive power injections $\left(Q_{s c 1} \ldots Q_{s c N s c}\right)$. The objective function (7) is described as a mixed continuous discrete optimization problem. The placement of STATCOM is considered as a discreet decision variable. Some constraints including entire power flow equations. The cost function Subject to: Equivalent constraints $g(x, u)$ :

$$
\begin{gathered}
P_{G i}-P_{D i}-V_{i} \sum_{j=1}^{n b} V_{j}\left[G_{i j} \cos \left(\delta_{i}-\delta_{j}\right)+B_{i j} \sin \left(\delta_{i}-\right.\right. \\
\left.\left.\delta_{j}\right)\right]=0 \\
Q_{G i}-Q_{D i}-V_{i} \sum_{j=1}^{n b} V_{j}\left[G_{i j} \sin \left(\delta_{i}-\delta_{j}\right)-B_{i j} \cos \left(\delta_{i}-\right.\right. \\
\left.\left.\delta_{j}\right)\right]=0
\end{gathered}
$$

Where $i=1,2 \ldots n b$ is the number of buses, $P_{G}$ and $Q_{G}$ are the generator real and reactive power respectively, $P_{D}$ and $Q_{D}$ are the real and reactive loads respectively, $B_{i j}$ is the transfer susceptance between bus $\mathrm{i}$ and bus $\mathrm{j}$ respectively.

Inequality constraints $h(x, u)$ :

Upper and lower limits on the active and reactive generations:

$$
\begin{array}{ll}
P_{G i}^{\min } \leq P_{G i} \leq P_{G n}^{\max } & \forall i \varepsilon n g \\
Q_{G i}^{\min } \leq Q_{G i} \leq Q_{G n}^{\max } & \forall i \varepsilon n g
\end{array}
$$

Upper and lower bounds in the bus voltage magnitude:

$$
\delta_{i j}^{\min } \leq \delta_{i j} \leq \delta_{i j}^{\max } \quad \forall i \varepsilon n g \quad\left(-45^{\circ} \text { to } 45^{\circ}\right)
$$

Upper and lower bounds in the STATCOM parameters:

$$
\mathrm{Q}_{\mathrm{SC}}^{\min } \leq \mathrm{Q}_{\mathrm{SC}} \leq \mathrm{Q}_{\mathrm{SC}}^{\max } \quad \text { (-20Mvar to 20Mvar) }
$$

Inequality constraints of the system voltage

$$
V_{i}^{\text {min }} \leq V_{i} \leq V_{i}^{\max }
$$

The bus voltages specified within $\pm 5 \%$ of the nominal value.

\subsection{Contingency Analysis and Power System Stress}

Stressed power system, either due to increasing loading or due to severe contingency, often lead to situation where system no longer remains in the secure operating region. The power system is generally stressed by means of several 
causes such as the variation of load and the outage of lines.

\subsubsection{Single Line Outages}

For optimal placement of STATCOM in a power system, single line outages are considered as contingencies in this paper and to evaluate the severity of a contingency, Voltage Power Index (VPI) has been used as:

$$
V P I=\sum_{i=1}^{N B}\left(\Delta\left|V_{i}\right| / \Delta\left|V_{i}^{\max }\right|\right)^{2 m}
$$

where, $\Delta\left|V_{i}\right|$ is absolute arithmetic difference between the voltage magnitude under line outage and base case condition; $\Delta\left|V_{i}^{\max }\right|$ is bus voltage magnitude selected by the utility engineers to specify how much they think is permissible limit for an outage case. $\Delta\left|V_{i}^{\max }\right|$ has been considered as 0.2 p.u.

\subsubsection{System Loadability}

The equality constraints are the load flow equations given by the relation:

$$
\begin{aligned}
& P_{G i}-\lambda P_{D i}=P_{i} \\
& Q_{G i}-\lambda Q_{D i}=Q_{i}
\end{aligned}
$$

$\lambda$ is the loadability factor in p.u. $P_{i}$ and $Q_{i}$ are real and reactive power loads at bus $i$.

\section{Grey Wolf Search Algorithm}

Grey wolves at the top of the food chain, mostly prefer to live in a pack. Of particular interest is that they have a very strict social dominant hierarchy as shown in Fig. 1.

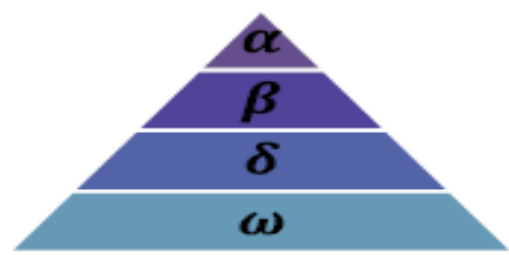

Figure 1. Hierarchy of grey wolf (dominance decreases from top down).

In the GWO algorithm the hunting (optimization) is guided by $\alpha, \beta$, and $\delta$. The $\omega$ wolves follow these three wolves.

Encircling prey: grey wolves encircle prey during the hunt. In order to mathematically model encircling behavior the following equations are proposed[4]:

$$
\begin{array}{r}
D=\left|C \cdot X_{P}(t)\right| \\
X(t+1)=X_{P}(t)-A \cdot D
\end{array}
$$

where $\mathrm{t}$ indicates the current iteration, $\mathrm{A}$ and $\mathrm{C}$ are coefficient vectors, $X_{p}$ is the position vector of the prey, and $\mathrm{X}$ indicates the position vector of a grey wolf. The vectors $\mathrm{A}$ and $\mathrm{C}$ are calculated as follows:

$$
\begin{gathered}
A=2 a \cdot r_{1}-a \\
C=2 \cdot r_{2}
\end{gathered}
$$

where components of a are linearly decreased from 2 to 0 over the course of iterations and $\mathrm{r}_{1}, \mathrm{r}_{2}$ are random vectors in $[0,1]$.

Hunting: In order to mathematically simulate the hunting behavior of grey wolves, suppose that the alpha (best candidate solution) beta, and delta have better knowledge about the potential location of prey. Therefore, we save the first three best solutions obtained so far and oblige the other search agents (including the omegas) to update their positions according to the position of the best search agents. The following formulas are proposed in this regard.

$$
\begin{gathered}
D_{\alpha}=\left|C_{1} \cdot X_{\alpha}-X\right|, D_{\beta}=\left|C_{2} \cdot X_{\beta}-X\right|, D_{\delta}=\left|C_{3} \cdot X_{\delta}-X\right| \\
X_{1}=X_{\alpha}-A_{1} \cdot\left(D_{\alpha}\right), X_{2}=X_{\beta}-A_{2} \cdot\left(D_{\beta}\right), X_{3}=X_{\delta}-A_{3} \\
\left(D_{\delta}\right) \\
X(t+1)=\frac{X_{1}+X_{2}+X_{3}}{3}
\end{gathered}
$$

\section{Studied Model}

The IEEE 30-bus power system has been selected for this study as shown in Figure 2.

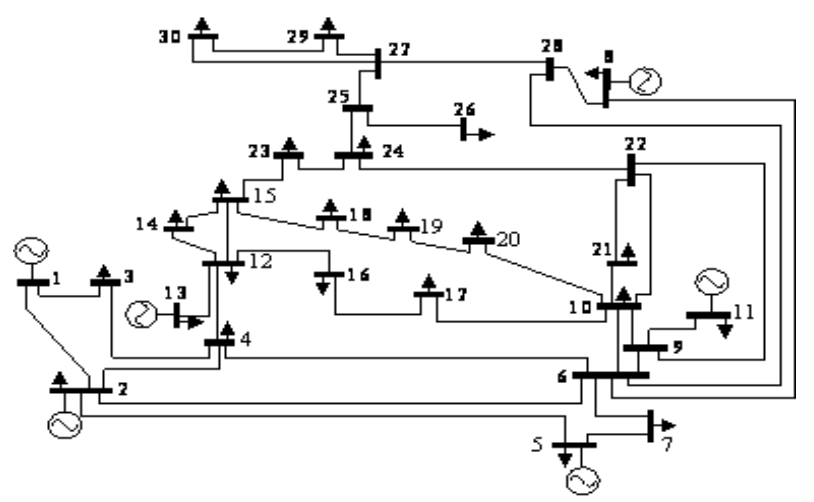

Figure 2. IEEE 30 Bus power system.

From the equivalent circuit of the STATCOM shown in Figure 3 let the voltage at bus $\mathrm{j}$ as $V_{j} \mid \delta_{j}$, the variable voltage (ac) at the output of STATCOM as $V_{j} \mid \delta_{j},\left(Y_{s c}=G_{s c}+j B_{s c}\right)$ is the STATCOM admittance and $Q_{s c}$ is the Reactive power exchange for the STATCOM with the bus. The STATCOM power flow constraints given in [21] are used for calculating the power flow analysis on the studied electrical network given in Figure 2. These constraints can be described from eq. (25) to eq. (28).

$$
\begin{array}{rr}
\left|V_{s c}\right|^{2} G_{s c}-\left|V_{s c}\right|\left|V_{j}\right|\left[G_{s c} \cos \left(\delta_{s c}-\delta_{j}\right)+B_{s c} \sin \left(\delta_{s c}-\delta_{j}\right)\right] \\
Q_{s c}=-\left|V_{s c}\right|^{2} B_{s c}-\left|V_{s c}\right|\left|V_{j}\right|\left[G_{s c} \sin \left(\delta_{s c}-\delta_{j}\right)-\right. \\
\left.B_{s c} \cos \left(\delta_{s c}-\delta_{j}\right)\right]
\end{array}
$$




$$
\left.\left.\delta_{s c}\right)\right]
$$
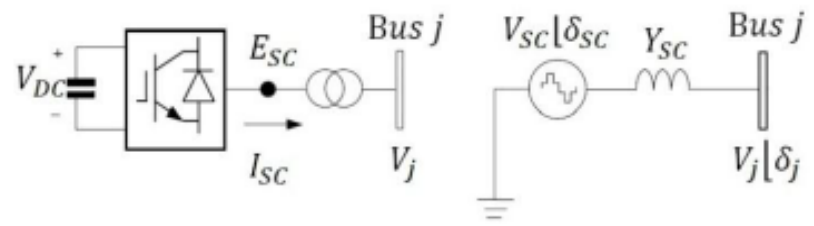

Figure 3. Static compensator (STATCOM) system.

\section{Simulations Results}

The GWO has been implemented to search with the following parameters:

Number of Search Agents :40;Number of iterations : 150

Number of variables (dimension of the problem) : 14

It is desirable to keep the voltage deviations near zero to avoid voltage collapses during faulty conditions. The base case and different two fault cases (single line outages and system loading ) have been carried out (Table 1) .

Table 1. THE BEST OPTIMAL SOLUTION OBTAINED BY GWO

$\begin{array}{cccc}\text { Case } & \begin{array}{c}\text { STATCOM } \\ \text { Location (Bus No.) }\end{array} & \begin{array}{c}\text { STATCOM Size } \\ \text { (Mvar) }\end{array} & \begin{array}{c}\text { Min.fitness } \\ \text { (Alpha-score) }\end{array} \\ 1 & \text { 30th,26th ,21th } & 2.631,2.344,-0.288 & 17.8187 \\ 2 & \text { 30th } & 15.19 & 27.8558 \\ 3 & \text { 30th ,26th ,22th } & 4.440,3.636,6.721 & 33.2976\end{array}$

\section{Case 1: base case}

A modify IEEE 30 bus network [26]. A fast solve of the fitness function by GWO shown in Fig. 4. The effect of optimization solution on the power system voltage profile (Fig. 5) and the successfully reduce in generation powers and system losses are illustrated in Table 2.

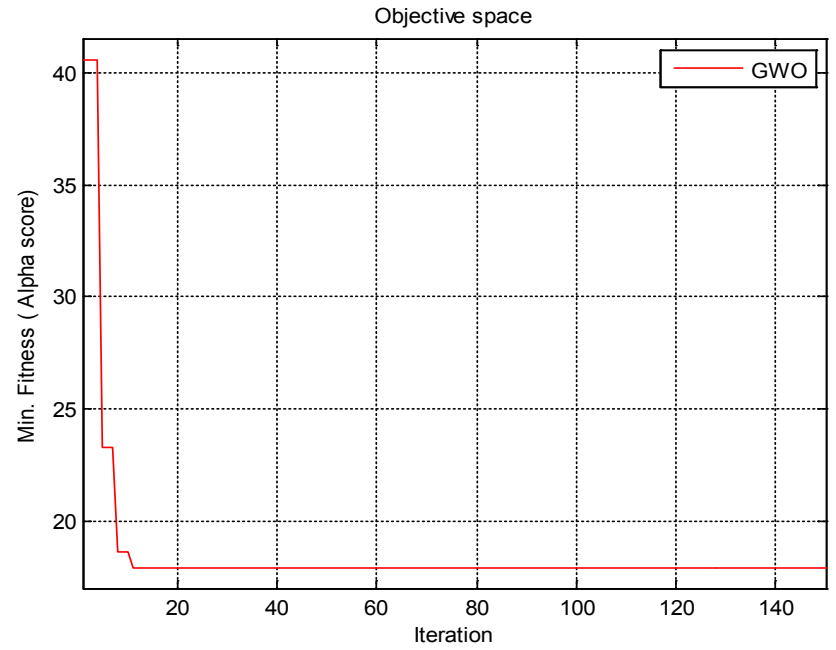

Figure 4. GWO Fitness function convergence curve for case 1
Table 2. COMPARISON OF GENERATION POWER CASE 1

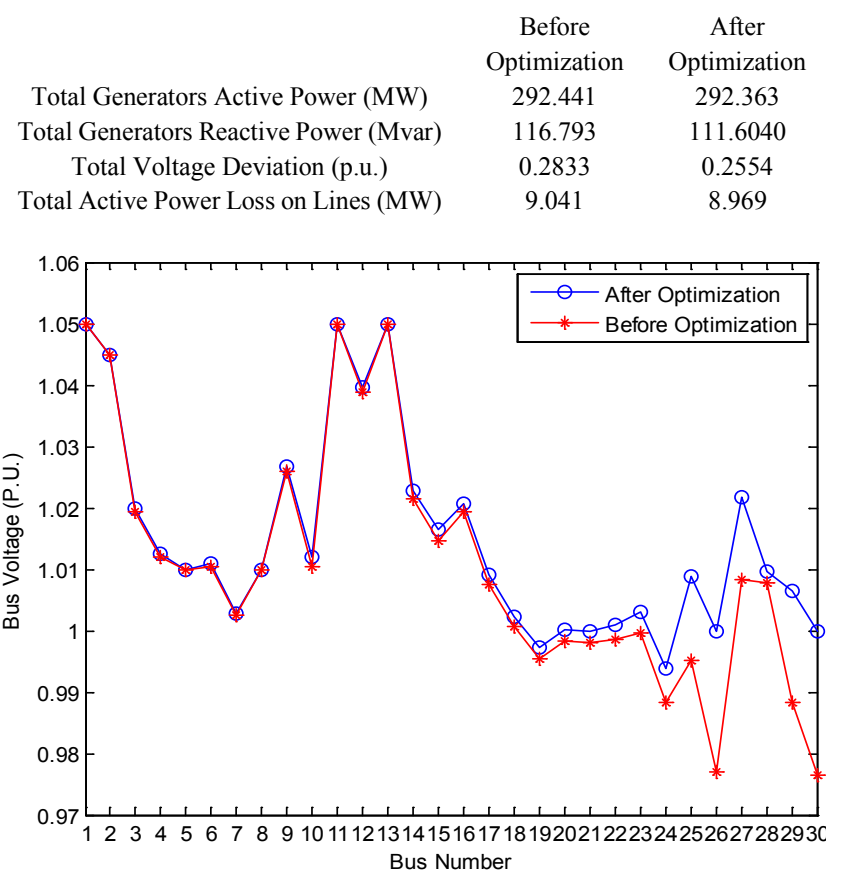

Figure 5. comparison of voltage profile case 1

\section{Case 2: single line outages}

For optimum allocation of STATCOM, single line outages are considered as contingencies in the test power system and to evaluate the severity of a contingency VPI is used. It has been observed that Newton Raphson load flow converges for only for 38 line outages out of 41 line outages. On the basis of VPI, the ranking of critical contingencies was done as 36 , 38,39 and 14 and so on, with corresponding values 2.1285 , $0.0293,0.065$ and 0.0156 . Only first most severe contingencies i.e. outage of line no. 36 have been considered for STATCOM placement. Fig.6 shows the convergence characteristic of GWO, while fig.7 illustrates the voltage profile of the test system without and with STATCOM at bus no. 30. The enhancement in the total performances of the power system as illustrated in table 3 .

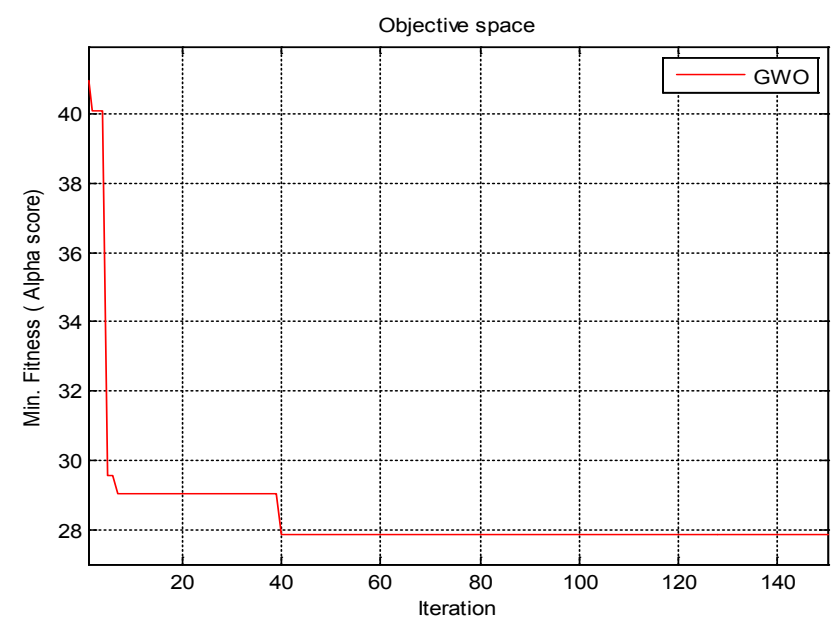

Figure 6. Convergence characteristic of GWO for outage of line no. 36. 


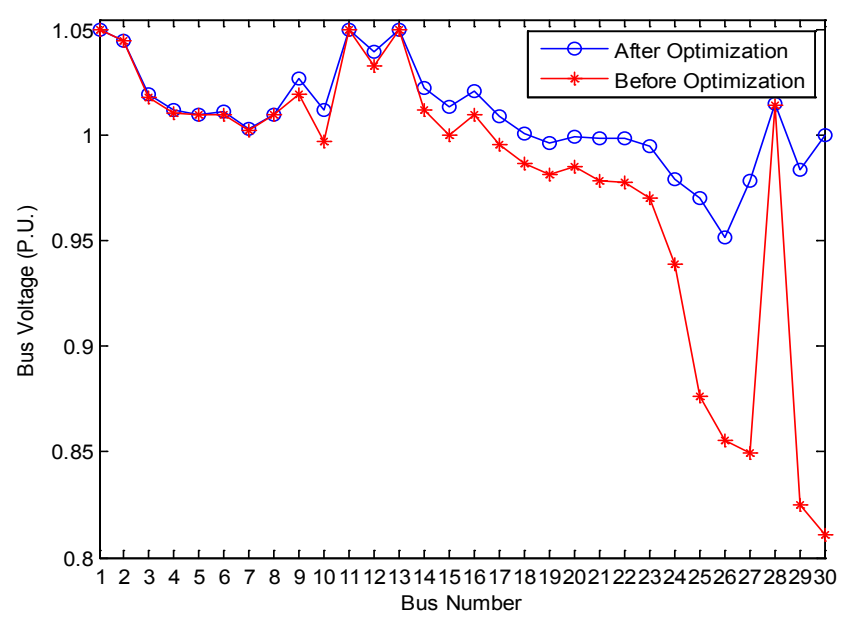

Figure 7. Comparison of voltage profile case 2

Table 3. COMPARISON OF GENERATION POWER CASE 2

$\begin{array}{ccc}\text { Total Generators Active Power } & \begin{array}{c}\text { Before } \\ \text { Optimization } \\ \text { (MW) }\end{array} & \begin{array}{c}\text { After } \\ \text { Optimization } \\ 295.136\end{array} \\ \begin{array}{c}\text { Total Generators Reactive Power } \\ \text { (Mvar) }\end{array} & 124.095 & 106.78 \\ \begin{array}{c}\text { Total Active Power Loss on Lines } \\ \text { (MW) }\end{array} & 11.736 & 11.311 \\ \begin{array}{c}\text { Injected Reactive power (Mvar) } \\ \text { Total Voltage Deviation (p.u.) }\end{array} & 0.0 & 15.19 \\ & 1.0986 & 0.3556\end{array}$

\section{Case 3: System Loadability}

The stress of power system is modeled by an increase the loadability factor $\lambda$ up to 1.2 , so an increase in the demand load power from (283.4MW 126.2Mvar) to (340.08MW 151.44Mvar). Without any modify in the generating powers in generation buses (PG buses). Solve the optimization problem with GWO, as can be seen from fig. 8 . The network without STATCOM devices has more voltage drop in the buses. This clearly shows the significant influence of STATCOM devices on keeping bus voltages in the acceptable range, as shown in Fig.9. The improvement in the total performances of the power system as illustrated in table 4.

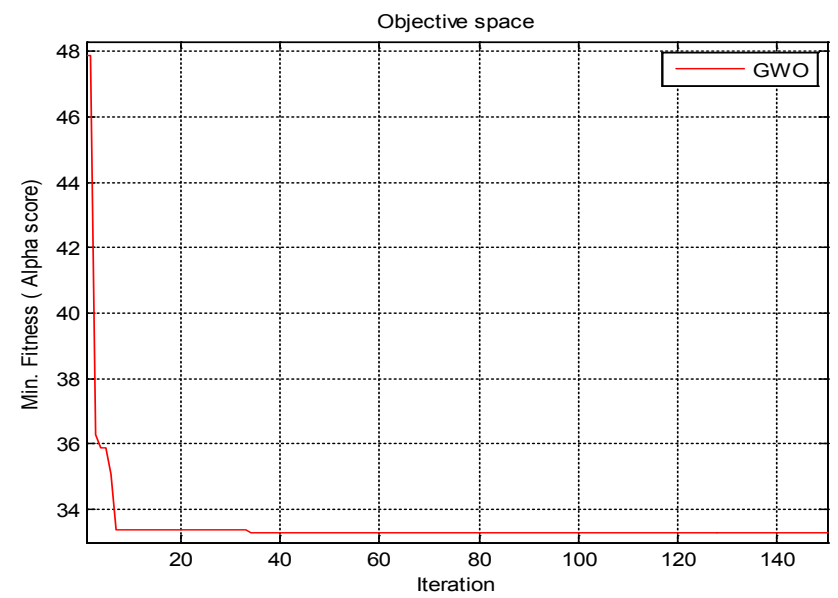

Figure 8. GWO Fitness function convergence curve for case 3

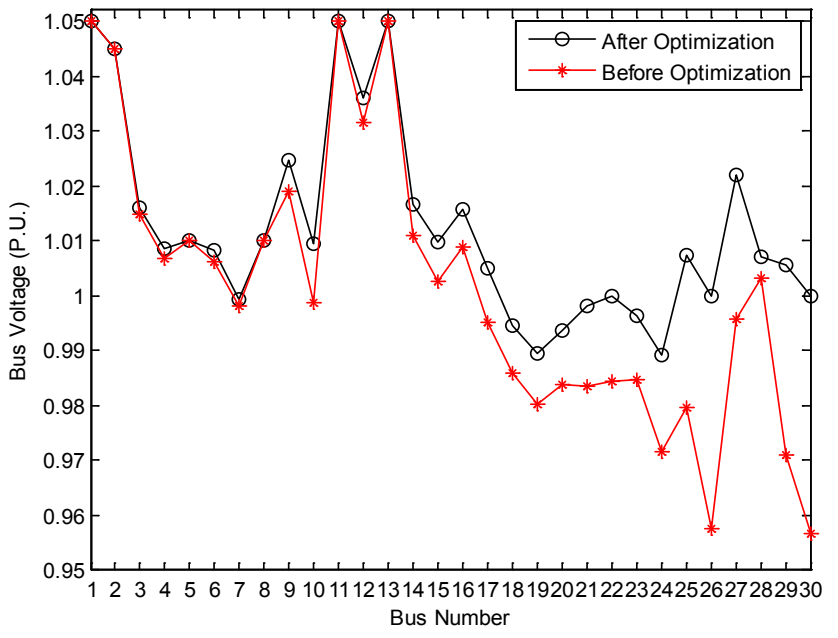

Figure 9. Comparison of voltage profile case 3

Table 4. COMPARISON OF GENERATION POWER CASE 3

\begin{tabular}{|c|c|c|}
\hline & $\begin{array}{c}\text { Before } \\
\text { Optimization }\end{array}$ & $\begin{array}{c}\text { After } \\
\text { Optimization }\end{array}$ \\
\hline Total Generators Active Power (MW) & 355.643 & 355.349 \\
\hline $\begin{array}{l}\text { Total Generators Reactive Power } \\
\text { (Mvar) }\end{array}$ & 167.470 & 150.7560 \\
\hline $\begin{array}{l}\text { Total Active Power Loss on Lines } \\
\text { (MW) }\end{array}$ & 15.563 & 15.269 \\
\hline Injected Reactive power (Mvar) & 0.0 & 14.797 \\
\hline Total Voltage Deviation (p.u.) & 0.3764 & 0.2319 \\
\hline
\end{tabular}

\section{Conclusions}

Grey Wolf Optimizer used for optimum number, location and size of STATCOM devices. GWO is proposed in order to improve the voltage profile and reduce the system losses, that clearer in IEEE 30 bus system. From the obtained results, it is obvious that sufficient enhancement in the steady-state security of the network and system loadability. The proposed GWO has shown superior features including high quality solution, stable convergence characteristics, good computational efficiency and mainly have a fast coverage to optimal solution.

\section{REFERENCES}

[1] Bonabeau E, Dorigo M, Theraulaz G. "Swarm intelligence: from natural to artificial systems", Oxford University Press, USA, 1999.

[2] Marco Dorigo, Thomas Stutzle, "Ant Colony Optimization", A Bradford Book, The MIT Press, 2006.

[3] Yuhui Shi ; Eberhart, R., Eberhart R." Modified Particle swarm optimizer", The 1998 IEEE International Conference on Computational Intelligence, 1998, pp. 69-73.

[4] Seyedali Mirjalili, Seyed Mohammad Mirjalili, Andrew Lewis, "Grey Wolf Optimizer", Advances in Engineering Software, Vol. 69, 2014, pp. 46-61. 
[5] Tao Xiang, Kwok-wo Wong, Xiaofeng Liao, "A novel particle swarm optimizer with time-delay" Applied Mathematics and Computation 186, 2007, pp. 789-793.

[6] Leandro dos Santos Coelho, "A quantum particle swarm optimizer with chaotic mutation operator" Chaos, Solitons and Fractals, Vol. 37, (2008), pp. 1409-1418.

[7] Rupam Kundu a, Swagatam Das b,n, Rohan Mukherjee a, Shantanab Debchoudhury, "An improved particle swarm optimizer with difference mean based perturbation" Neurocomputing, Vol. 129, 2014, pp. 315-333.

[8] Yixiong Feng, Bing Zheng, Zhongkai Li, " Exploratory study of sorting particle swarm optimizer for multiobjective design optimization" Mathematical and Computer Modelling, Vol. 52, (2010), pp. 1966-1975.

[9] Prithwish Chakraborty, Swagatam Das, Gourab Ghosh Roy, Ajith Abraham, " Erratum to On convergence of the multi-objective particle swarm optimizers" Information Sciences 181 (2011) 3533

[10] Xueming Yang, Jinsha Yuan, Jiangye Yuan, Huina Mao, " A modified particle swarm optimizer with dynamic adaptation" Applied Mathematics and Computation, Vol. 189, (2007), pp. 1205-1213.

[11] XU Jun-jie, YUE Xin, XIN Zhan-hong, "Research of stochastic weight strategy for extended particle swarm optimizer" The Journal of China Universities of Posts and Telecommunications, Vol.15, Issue 2, June 2008, pp. 122-125.

[12] Xuewen Xia, Jingnan Liu, Zhongbo Hu, " An improved particle swarm optimizer based on tabu detecting andlocal learning strategy in a shrunk search space" Applied Soft Computing, Vol. 23, 2014, pp. 76-90.

[13] Jin Yisu, Joshua Knowles, Lu Hongmei, Liang Yizeng, Douglas B. Kell, "The landscape adaptive particle swarm optimizer", Applied Soft Computing, Vol. 8, 2008, pp. 295304.

[14] Sidhartha Panda, "Multi-objective PID controller tuning for a FACTS-based damping stabilizer using Non-dominated Sorting Genetic Algorithm-II" Electrical Power and Energy Systems Vol. 33, 2011, pp. 1296-1308.

[15] T. Nireekshana, G. Kesava Rao, S. Siva Naga Raju, "Enhancement of ATC with FACTS devices using Real-code Genetic Algorithm", Electrical Power and Energy Systems, Vol. 43, 2012, pp. 1276-1284.

[16] Sidhartha Panda, Narayana Prasad Padhy, "Comparison of particle swarm optimization and genetic algorithm for FACTS-based controller design" Applied Soft Computing, Vol. 8, 2008, pp. 1418-1427.

[17] J. Preetha Roselyn, D. Devaraj, Subhransu Sekhar Dash, "Multi-Objective Genetic Algorithm for voltage stability enhancement using rescheduling and FACTS devices" Ain Shams Engineering Journal, Vol. 5, 2014, pp. 789-801.

[18] M. Saravanan, S. Mary Raja Slochanal, P. Venkatesh, J. Prince Stephen Abraham, "Application of particle swarm optimization technique for optimal location of FACTS devices considering cost of installation and system loadability" Electric Power Systems Research, Vol. 77, 2007, pp. 276-283.

[19] K. Ravi, M. Rajaram, "Optimal location of FACTS devices using Improved Particle Swarm Optimization" Electrical Power and Energy Systems, Vol. 49, 2013, pp. 333-338.

[20] Y.C. Chang, "Transmission system loading margin enhancement with ordinal optimization based STATCOM installation strategy", Electrical Power and Energy Systems, Vol. 55, 2014, pp. 503-510.

[21] G. Sasank Das, B. Mohan, "Optimal Allocation of FACTS Device with Multiple Objectives Using Genetic Algorithm", International Journal Of Modern Engineering Research (IJMER), Vol. 4, Iss. 2, Feb. 2014, pp. 162-168.

[22] V. Petridis, S. Kazarlis, A. Bakirtzis, "Varying Fitness Functions in Genetic Algorithm Constrained Optimization", IEEE Transactions On Systems, Man, and Cybernetics Part B, VOL. 28, NO. 5, October 1998, pp. 629 - 640.

[23] Abido, M. A. "Optimal power flow using particle swarm optimization." International Journal of Electrical Power \& Energy Systems, Vol 24, 2002,pp.563-571

[24] J. Namratha Manohar, J.Amarnath,"Enhancement of Available Transfer Capability Using Facts Devices and Evaluation of Economics of Operating De-Regulated Power Systems",Int. J. of Advanced Research in Electrical, Electronics and Instrumentation Engineering, Vol.3, Issue 1, Jan. 2014, pp. 6747-6761.

[25] R.Kalaivani, S.K.Dheebika,"Application of Soft Computing Technique to Avoid Voltage Collapse in Power System", International Journal of Engineering and Technology (IJET), Vol 5 No 6, Jan 2014, pp 5079-5087.

[26] Alsac and B. Stott, "Optimal load flow with steady-state security," Power Apparatus and Systems, IEEE Transactions,vol. PAS-93, may 1974, pp. $745-751$. 